\title{
Ileostomy or colostomy for temporary decompression of colorectal anastomosis. Systematic review and meta-analysis ${ }^{1}$
}

\author{
Ileostomia ou colostomia na descompressão temporária de anastomose colorretal. Revisão \\ sistemática da literatura e metanálise
}

\author{
Katia Ferreira Güenaga', Suzana Angélica Silva Lustosa ${ }^{I I}$, Sarhan Sydney Saad ${ }^{\mathrm{III}}$, Humberto Saconato ${ }^{\mathrm{IV}}$, Delcio Matos ${ }^{\mathrm{V}}$

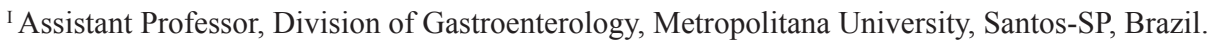

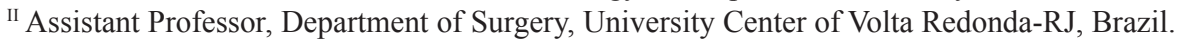 \\ III Associate Professor, Division of Surgical Gastroenterology, Department of Surgery, Federal University of São Paulo (UNIFESP), Brazil. \\ IV Reviewer, Brazilian Cochrane Center, UNIFESP, São Paulo, Brazil. \\ ${ }^{v}$ Full Professor, Division of Surgical Gastroenterology, Department of Surgery, UNIFESP and Metropolitana University of Santos. Dean of \\ Postgraduate Program of Surgical Gastroenterology, UNIFESP, Brazil.
}

\begin{abstract}
Purpose: The controversy regarding whether loop ileostomy or loop transverse colostomy is a better method for temporary decompression of colorectal anastomosis motivated this review. Methods: Five randomized trials were included, with 334 patients: 168 in the loop ileostomy group and 166 in the loop transverse colostomy group. The outcomes analyzed were: 1 . Mortality; 2. Wound infection; 3. Time of stoma formation; 4. Time of stoma closure; 5 . Time interval between stoma formation and closure; 6. Stoma prolapse; 7. Stoma retraction; 8. Parastomal hernia; 9. Parastomal fistula; 10. Stenosis; 11. Necrosis; 12. Skin irritation; 13. Ileus; 14. Bowel leakage; 15. Reoperation; 16. Patient adaptation; 17. Length of hospital stay; 18. Colorectal anastomotic dehiscence; 19. Incisional hernia; 20. Postoperative bowel obstruction. Results: Stoma prolapse was statistically significant $(\mathrm{p}=0.00001)$, but with statistical heterogeneity; the sensitive analysis was applied, excluding the trials that included emergency surgery, and this showed: $\mathrm{p}=0.02$, with $\mathrm{I}^{2}=0 \%$ for the heterogeneity test. Conclusions: The outcomes reported were not statistically or clinically significant except for stoma prolapse. Better evidence for making the choice between loop ileostomy or loop colostomy requires large-scale randomized controlled trials.
\end{abstract}

Key words: Ileostomy. Colostomy. Colorectal surgery. Systematic review. Meta-analysis.

\section{RESUMO}

Objetivo: A controvérsia entre ileostomia em alça ou colostomia em alça como a melhor forma para a descompressão temporária da anastomose colorretal motivou a realização desta revisão. Métodos: Cinco ensaios clínicos casualizados foram incluídos com 334 pacientes: 168 no grupo de ileostomia e 166 no grupo de colostomia. Os resultados analisaram: 1. Mortalidade; 2. Infecção da ferida; 3. Tempo de formação do estoma; 4. Tempo de fechamento do estoma; 5. Intervalo de tempo entre a formação e o fechamento do estoma; 6. Prolapso do estoma; 7. Retração do estoma; 8. Hérnia parastomal; 9. Fistula parastomal; 10. Estenose; 11. Necrose; 12. Irritação de pele; 13. Íleo; 14. Fístula entérica; 15. Reoperação; 16. Adaptação do paciente; 17. Tempo de internação hospitalar; 18. Deiscência da anastomose colorretal; 19. Hérnia de Incisional; 20. Obstrução intestinal pós-operatória. Resultados: Prolapso do estoma: $\mathrm{p}=0.00001$, mas com heterogeneidade estatística; a análise de sensibilidade foi aplicada excluindo os estudos que incluíram cirurgias de emergência: $p=0.02$ e teste de heterogeneidade: $\mathrm{I}^{2}=0 \%$. Conclusões: Os resultados encontrados não foram estatística ou clinicamente significantes, exceto prolapso do estoma. A melhor evidência para a escolha entre ileostomia em alça ou colostomia em alça necessita de maior número de ensaios clínicos.

Descritores: Ileostomia. Colostomia. Cirurgia colorretal. Revisão sistemática, Metanálise.

1. Work supported by Brazilian Cochrane Center, São Paulo, Brazil and Colorectal Cancer Group of Cochrane Collaboration, Kopenhagen, DK.

\section{Introduction}

Anastomotic leakage is one of the most important surgical complications of colorectal surgery. It has been of great concern because of high occurrence of morbidity and mortality, which affect long-term survival ${ }^{1}$. The use of a protective stoma should be considered in relation to specific conditions involving the operation (low tumor, narrow male pelvis or complications during construction of the anastomosis), or other situations such as: when the patient's initial condition is poor, after neoadjuvant radio chemotherapy, after total mesorectal excision, with preoperative steroid use, or with long-duration op- 
erations $\mathrm{s}^{2,3}$. The proximal diversion, by means of either a colostomy or an ileostomy, minimizes the consequences of anastomotic leakage by preventing faecal flow through the anastomo$\operatorname{sis}^{4-8}$. In a randomized multicenter trial ${ }^{9}$ it was shown that the defunctioning loop stoma decreased the rate of symptomatic anastomotic leakage. Some controversy still remains as to whether loop ileostomy or loop colostomy is the best way of defunctioning such anastomosis. Some randomized controlled trials have been reported but there is still no consensus. In a survey among colorectal surgeons involved in colorectal residency programs the data obtained showed a preference for loop ileostomy as a temporary stoma ${ }^{10}$. No convincingly significant differences in complications rates between the two methods have yet been presented, particularly with regard to stoma-related techniques ${ }^{11,12,13}$. Four randomized controlled trials have compared these two different techniques for defunctioning colorectal anastomosis. Two have favored loop transverse colostomy ${ }^{12,14}$, and two have recommended ileostomy ${ }^{11,15}$. In other non-randomized studies, construction of a loop ileostomy has been the preference, in the absence of any hard evidence favoring loop colostomy ${ }^{16,17,18}$. Both types of stoma present high complication rates, with considerable mortality rates ${ }^{19}$. The interval between stoma construction and closure usually has a substantial impact on social and economic status. Furthermore, quality-of- life issues need to be addressed ${ }^{20}$, as there seems to be a clear relationship between stoma care problems and the degree of social restriction. Thus, not only is a careful surgical technique required, but also the stoma type has to be carefully chosen in order to have a healthy stoma ${ }^{21}$. Clearly, it remains controversial as to whether loop ileostomy or loop colostomy is the most favourable proximal diversion for colorectal anastomosis.

The objective of this review was to evaluate the evidence regarding loop ileostomy versus loop transverse colostomy for temporary decompression of colorectal anastomosis.

\section{Methods}

All published and unpublished randomized controlled trials comparing loop ileostomy with loop transverse colostomy for temporary decompression of colorectal anastomosis were included. There were no restrictions on the patient's age or gender. The following bibliographic databases were searched: Cochrane Central Register of Controlled Trials (CENTRAL) (Cochrane Library, Issue 2, 2005), MEDLINE (from 1966 to April 2005), EMBASE (from 1980 to April 2005), LILACS (from 1988 to April 2005) and Cochrane Colorectal Cancer Group specialized register SR-COLOCA (Figure 1).

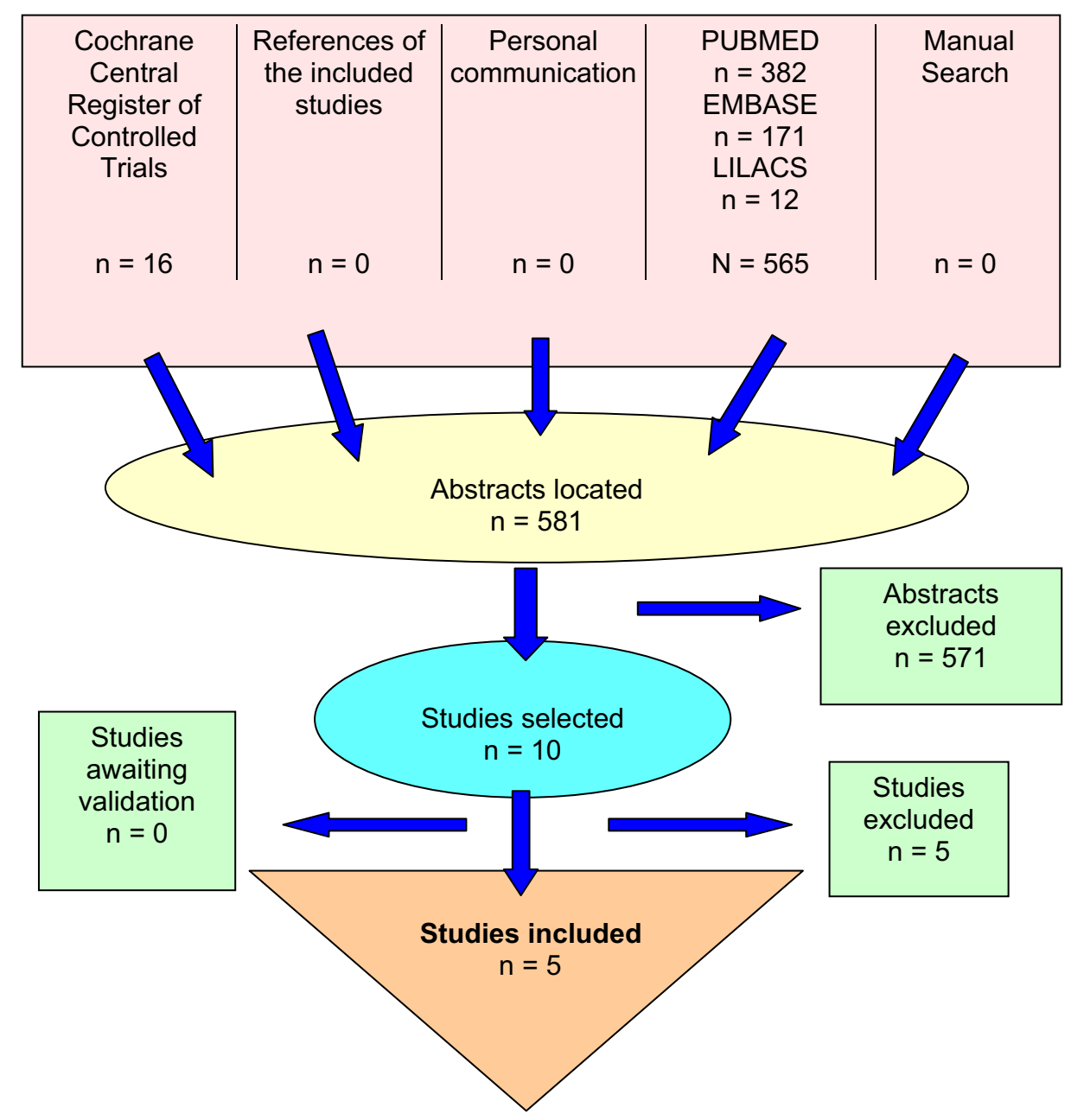

FIGURE 1 - Demonstrative flowchart of the result from the database search, selection and inclusion of articles in the systematic review 
The outcome measurements were divided into four categories:

A - General outcome measurements: mortality, wound infection, time interval between stoma formation and closure, length of hospital stay, reoperation and colorectal anastomotic dehiscence (Table 1).

TABLE 1 - General outcome measurements

\begin{tabular}{|c|l|l|}
\hline \multicolumn{1}{|c|}{ OUTCOME } & \multicolumn{1}{|c|}{ DEFINITION } \\
\hline 1. & Mortality & Number of deaths due to stoma formation or closure \\
\hline 2. & Wound infection & $\begin{array}{l}\text { Discharge of pus from the abdominal wound following } \\
\text { stoma formation or closure }\end{array}$ \\
\hline 3. & $\begin{array}{l}\text { Time interval between stoma } \\
\text { formation and closure }\end{array}$ & Time taken from stoma construction to closure \\
\hline 4. & Length of hospital stay & $\begin{array}{l}\text { Time elapsed between the operation for stoma formation } \\
\text { or closure and hospital discharge }\end{array}$ \\
\hline 5. & Reoperation & $\begin{array}{l}\text { Need for reoperation on the patient due to stoma } \\
\text { complication following stoma formation or closure }\end{array}$ \\
\hline Colorectal anastomotic & $\begin{array}{l}\text { dehiscence } \\
\text { externalized through the drainage opening or the wound } \\
\text { incision, or just the existence of an abscess adjacent to } \\
\text { the anastomosis site. The anastomotic leakage was } \\
\text { confirmed by either clinical or radiological investigation }\end{array}$ \\
\hline
\end{tabular}

B - Outcome measurements relating to stoma construction: time of formation, stoma prolapse, stoma retraction, stoma necrosis, parastomal hernia, parastomal fistula and stoma stenosis (Table 2).

TABLE 2 - Outcome measurements relating to stoma construction

\begin{tabular}{|c|l|l|}
\hline & \multicolumn{1}{|c|}{ OUTCOME } & \multicolumn{1}{c|}{ DEFINITION } \\
\hline 1. & Time of stoma formation & Time taken to perform the stoma \\
\hline 2. & Stoma prolapse & Eversion of the stoma through the abdominal wall \\
\hline 3. & Stoma retraction & Deepening of the stoma into the peritoneal cavity \\
\hline 4. & Parastomal hernia & Formation of a hernia beside the stoma \\
\hline $\mathbf{5 .}$ & Parastomal fistula & Intestinal leakage from the bowel in the stoma site \\
\hline $\mathbf{6 .}$ & Stenosis & Narrowing of the stoma lumen \\
\hline 7. & Necrosis & Vascular ischemic alteration of the bowel in the stoma \\
\hline
\end{tabular}

C - Outcome measurements relating to stoma closure: bowel leakage, time of stoma closure, incisional hernia and postoperative bowel obstruction (Table 3).

TABLE 3 - Outcome measurements relating to stoma closure

\begin{tabular}{|c|l|l|}
\hline & \multicolumn{1}{|c|}{ OUTCOME } & \multicolumn{1}{c|}{ DEFINITION } \\
\hline $\mathbf{1 .}$ & Bowel leakage & Leakage from the bowel after stoma the closure \\
\hline $\mathbf{2 .}$ & Time of stoma closure & Time taken to restore bowel continuity \\
\hline $\mathbf{3 .}$ & Incisional hernia & Formation of a hernia after closure of the stoma site \\
\hline $\mathbf{4 .}$ & $\begin{array}{l}\text { Postoperative bowel } \\
\text { obstruction }\end{array}$ & $\begin{array}{l}\text { Any mechanical obstruction of bowel that requires } \\
\text { conservative or surgical treatment }\end{array}$ \\
\hline
\end{tabular}


D - Outcome measurements relating to stoma functioning: patient adaptation, skin irritation and postoperative ileus (Table 4).

TABLE 4 - Outcome measurements relating to stoma functioning

\begin{tabular}{|c|c|c|}
\hline & OUTCOME & DEFINITION \\
\hline 1. & Skin irritation & Symptomatic alteration of the parastomal skin \\
\hline 2. & Ileus & Temporary bowel dysfunction after stoma closure \\
\hline 3. & Patient adaptation & $\begin{array}{l}\text { Leakage from the appliance, number of appliances } \\
\text { changes required per day, dietary alterations, need for } \\
\text { medication, degree of odor and flatus from the stoma and } \\
\text { psychosocial sequelae }\end{array}$ \\
\hline
\end{tabular}

The methodological quality of each trial was assessed by the reviewers. The following pre-specified characteristics of all the randomized controlled trials included were extracted:

- Methods: diagnostic procedures, randomization procedure, allocation concealment, sample size calculation and length of follow-up.

- Participants: disease classification, age, number of patients randomized and reasons for withdrawal from the study.

- Interventions: loop ileostomy and loop colostomy.

Validation studies were investigated by analyzing the participants, interventions and outcome measurements. The studies were stratified for meta-analysis according to the above items and also their clinical homogeneity. For dichotomous outcome measurements, the meta-analysis was performed using risk difference (RD) and relative risk (RR), with the corresponding $95 \%$ confidence intervals $(95 \% \mathrm{CI})$. The fixed-effect model was used for all outcomes except one, incisional hernia, because this outcome presented significant heterogeneity among the trials. Random-effect meta-analysis was therefore used for the outcome of incisional hernia.

The statistical heterogeneity in the results from the meta-analyses was assessed by inspection of graphical presentations (funnel plot) and by calculating a heterogeneity test (standard chisquare test on $\mathrm{N}$ degrees of freedom, where $\mathrm{N}$ equals the number of trials minus one).

Sensitivity analysis was performed by excluding studies in which there was some ambiguity as to whether they meet the inclusion criteria. The studies excluded were those that had included emergency surgery or higher colorectal anastomosis.

\section{Results}

Five studies met the inclusion criteria ${ }^{11-15}$. These studies involved 334 patients: 168 in the loop ileostomy group and 166 in the loop colostomy group. Two of the trials ${ }^{13,14}$ included only patients who underwent anterior resection and total mesorectal excision for rectal cancer. The other three trials ${ }^{11,12,15}$ analyzed patients who underwent surgery on the left-side colon and rectum. One of them ${ }^{12}$ included emergency operations. Four of the studies included ${ }^{11,12,14,15}$ described the stomas construction technique. Three studies ${ }^{11,13,15}$ reported that the deaths among their patients were not attributable to either formation or closure of the stoma. One trial ${ }^{14}$ described three deaths during the early postoperative period following stoma construction. One study ${ }^{15}$ analyzed the outcome of incisional hernia in the stoma wounds that were observed up to 2.5 years after closure. All of the five trials described the statistical analysis. Only one study ${ }^{14}$ described the sample size calculation with the outcome "small bowel obstruction". The methodological quality was evaluated independently by the reviewers. The methods used for generating the allocation sequence and allocation concealment were assessed. The allocation sequence was regarded as adequate in one study ${ }^{11}$, and unclear in the other four ${ }^{12-15}$. The allocation concealment was regarded as adequate in three trials ${ }^{13,14,15}$, and unclear in two trials ${ }^{11,12}$. The statistical analysis was presented using RD and RR with the corresponding 95\% CI. The total number of patients included in the meta-analysis was 334 patients: 168 in the loop ileostomy group (Group A) and 166 in the loop colostomy group (Group B). There was insufficient data to describe the continuous outcomes, since the reviewers would have needed the results from each patient, which were not presented in the trials. A number of outcomes are not presented graphically, because these events were only reported in one trial, or because their sample sizes were inadequate: steno$\operatorname{sis}^{12}$, necrosis ${ }^{12}$ and the patient adaptation outcomes of: number of appliances changes required per day ${ }^{11}$, dietary alteration ${ }^{12}$, need for medication and degree of odour ${ }^{15}$. Two of patient adaptation subcategories were not analyzed in any of the trials included: flatus from the stoma and psychosocial sequelae.

\section{A - General outcome measurements}

1. Mortality: $2 \%$ (3 out 160 patients) in Group A, compared with $0 \%$ ( 0 out 159 patients) in Group B; RD 0.02, 95\% CI: 0.02 to 0.05 (non-significant). There was no statistical heterogeneity in this comparison: heterogeneity chi-square test $=1.66$, $\mathrm{df}=4, \mathrm{p}=0.80, \mathrm{I}^{2}=0 \%$. Described in all trials included (Figure 2).

2. Wound infection: $8 \%$ (12 out 150 patients) in Group A, compared with $14 \%$ (21 out 155 patients) in Group B; RR 0.57, $95 \%$ CI: 0.31 to 1.07 (non-significant; $p=0.08$ ). There was no statistical heterogeneity in this comparison: heterogeneity chisquare test $=3.56, \mathrm{df}=4, \mathrm{p}=0.47, \mathrm{I}^{2}=0 \%$. Described in all 
trials included.

3. Colorectal anastomotic dehiscence: $9 \%$ (11 out 127 patients) in Group A, compared with 12\% (15 out 123 patients) in Group B; RR $0.72,95 \%$ CI: 0.36 to 1.47 (non-significant). There was no statistical heterogeneity in this comparison: heterogeneity chi-square test $=2.26, \mathrm{df}=3, \mathrm{p}=0.52, \mathrm{I}^{2}=0 \%$. Described in four trials ${ }^{11,13,14,15}$.

4. Reoperation: $3 \%$ ( 2 out 62 patients) in Group A, compared to $2 \%$ ( 1 out 56 patients) in Group B; RD 0.01, 95\% CI: -0.06 to 0.09 (non-significant). There was no statistical heterogeneity in this comparison: heterogeneity chi-square test $=1.68, \mathrm{df}=1$, $\mathrm{p}=0.19, \mathrm{I}^{2}=40.6 \%$. Described in two trials $\mathrm{s}^{14,15}$.

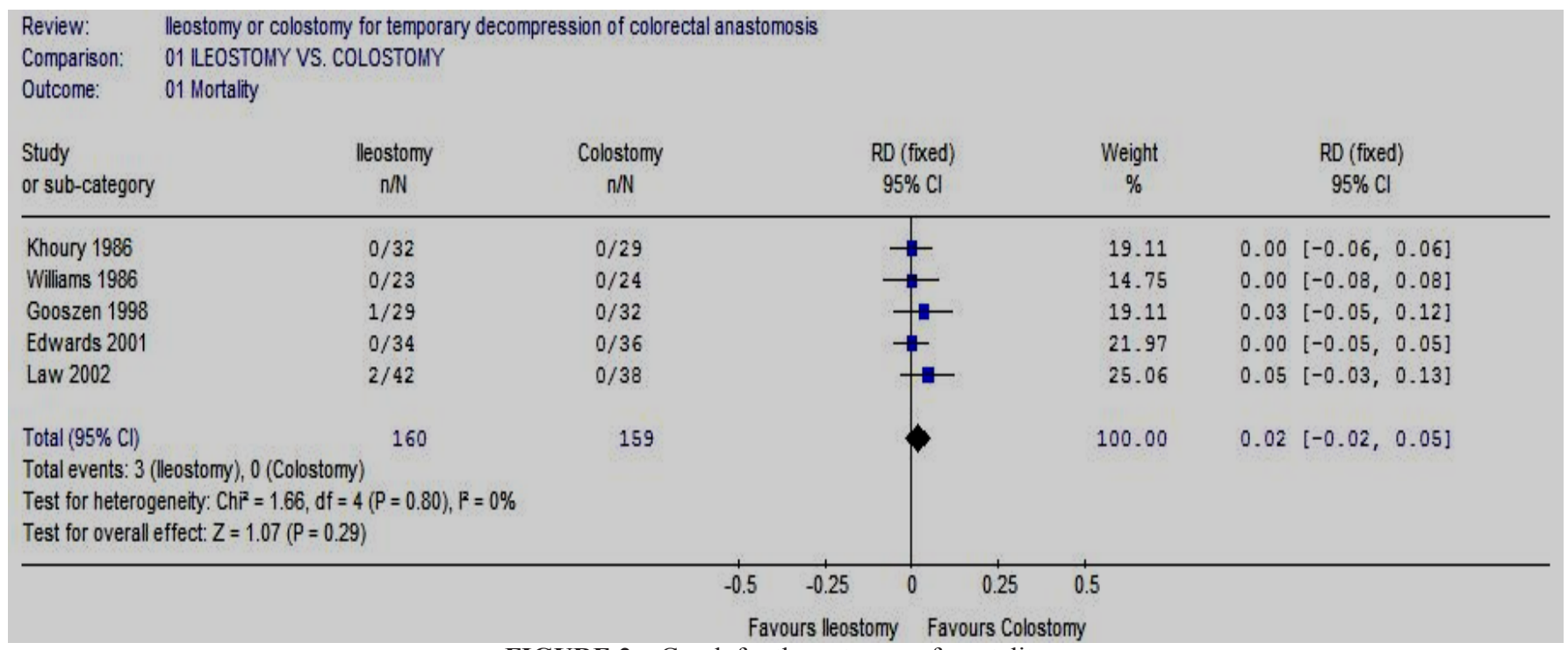

FIGURE 2 - Graph for the outcome of mortality

\section{B - Outcomes relating to stoma construction}

1. Stoma prolapse: $2 \%$ ( 2 out 125 patients) in Group A, compared with 19\% (25 out 131 patients) in Group B; RD -0.17, 95\% CI: -0.24 to $-0.10(\mathrm{p}<0.00001)$ (Figure 2$)$. There was statistical heterogeneity in this comparison: heterogeneity chisquare test $=15.00, \mathrm{df}=3, \mathrm{p}=0.001, \mathrm{I}^{2}=81.2 \%$ (Figure 3 ). Described in four studies ${ }^{12-15}$.

2. Stoma retraction: 4\% (4 out 106 patients) in Group A, compared with $1 \%$ ( 1 out 105 patients) in Group B; RD 0.03, 95\% CI: -0.02 to 0.08 (non-significant). There was no statistical heterogeneity in this comparison: heterogeneity chi-square test
$=3.93, \mathrm{df}=2, \mathrm{p}=0.14, \mathrm{I}^{2}=49.1 \%$. Described in three studies $^{11,12,14}$.

3. Parastomal hernia: 3\% (3 out 108 patients) in Group A, compared with 2\% (2 out 112 patients) in Group B; RD 0.01, 95\% CI: -0.04 to 0.06 (non-significant). There was no statistical heterogeneity in this comparison: heterogeneity chi-square test $=$ $3.34, \mathrm{df}=2, \mathrm{p}=0.19, \mathrm{I}^{2}=40.1 \%$. In three studies ${ }^{12-14}$.

4. Parastomal fistula: 3\% (2 out 64 patients) in Group A, compared with 4\% (3 out 67 patients) in Group B; RR 0.71, 95\% CI: 0.12 to 4.17 (non-significant). There was no statistical heterogeneity in this comparison: heterogeneity chi-square test $=0.05$, $\mathrm{df}=1, \mathrm{p}=0.82, \mathrm{I}^{2}=0 \%$. Described in two trials ${ }^{11,12}$.

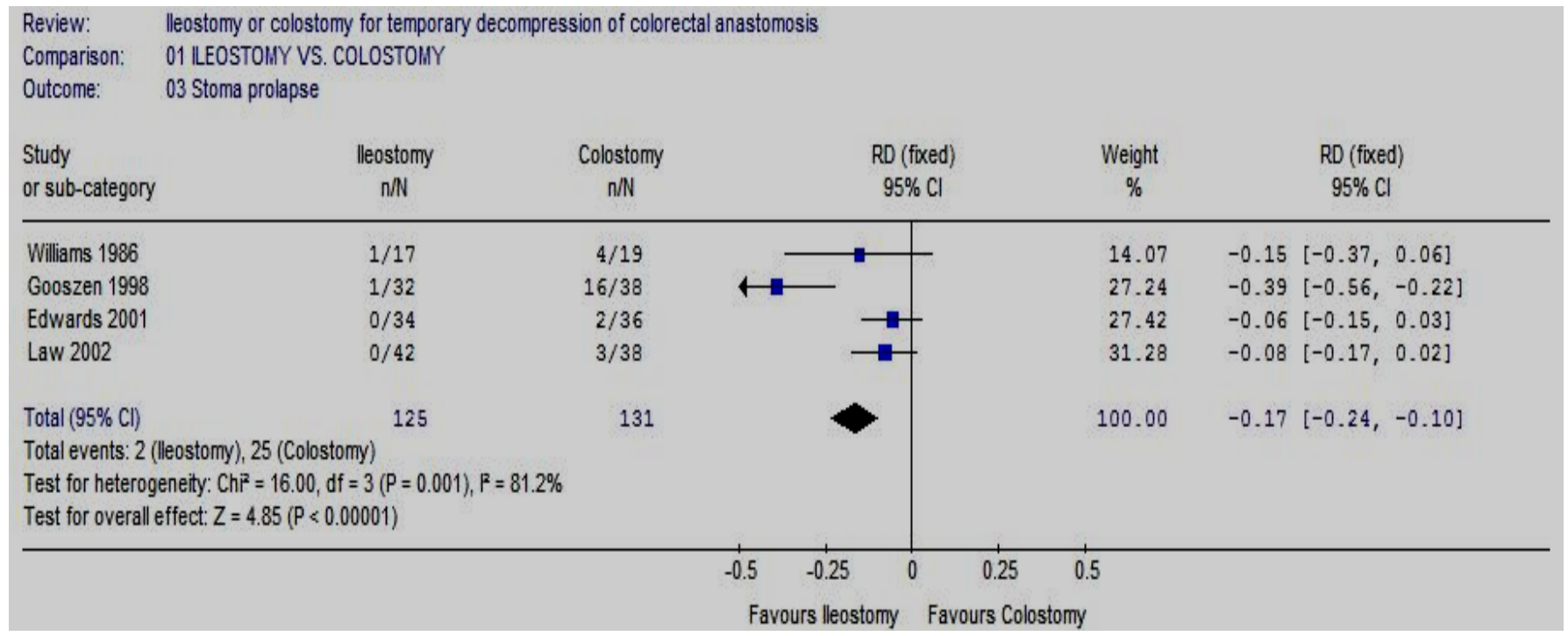

FIGURE 3 - Graph for the outcome of stoma prolapse 
The funnel plot for the meta-analysis on stoma pro- of one study distant from the mean line (Figure 4). lapse demonstrated asymmetry in its result, with the presence

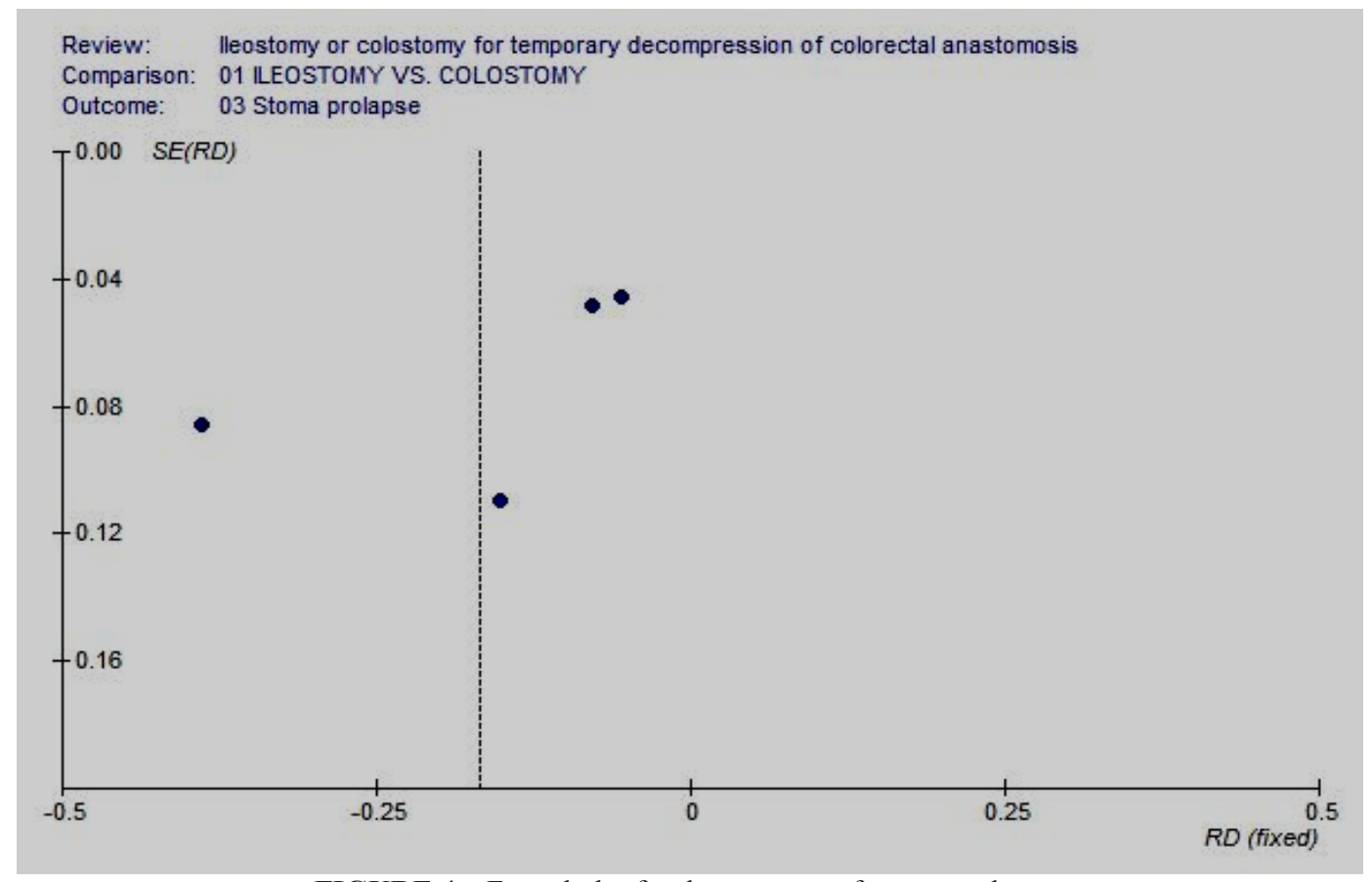

FIGURE 4 - Funnel plot for the outcome of stoma prolapse

\section{C - Outcomes relating to stoma closure}

1. Bowel leakage: $4 \%$ (5 out 128 patients) in Group A, compared with 2\% (3 out 130 patients) in Group B; RD 0.02, 95\% CI: -0.03 to 0.06 (non-significant). There was no statistical heterogeneity in this comparison: heterogeneity chi-square test $=2.32, \mathrm{df}=3, \mathrm{p}=0.51, \mathrm{I}^{2}=0 \%$. Described in four trials $\mathrm{s}^{11-14}$ (Figure 5).

2. Incisional hernia: $0 \%$ (0 out 52 patients) in Group A, compared with $10 \%$ (5 out 51 patients) in Group B; RD -0.07 ,
95\% CI: -0.26 to 0.11 (non-significant), in random-effect metaanalysis. There was statistical heterogeneity in this comparison: heterogeneity chi-square test $=5.20, \mathrm{df}=1, \mathrm{p}=0.04, \mathrm{I}^{2}=$ $80.8 \%$. Described in two trials ${ }^{13,15}$.

3. Postoperative bowel obstruction: $5 \%$ (6 out 119 patients) in Group A, compared with 4\% (5 out 118 patients) in Group B; RD 0.01, 95\% CI: -0.05 to 0.07 (non-significant). There was no statistical heterogeneity in this comparison: heterogeneity chi-square test $=2.67, \mathrm{df}=3, \mathrm{p}=0.45, \mathrm{I}^{2}=0 \%$. Described in four studies ${ }^{11,13,14,15}$.

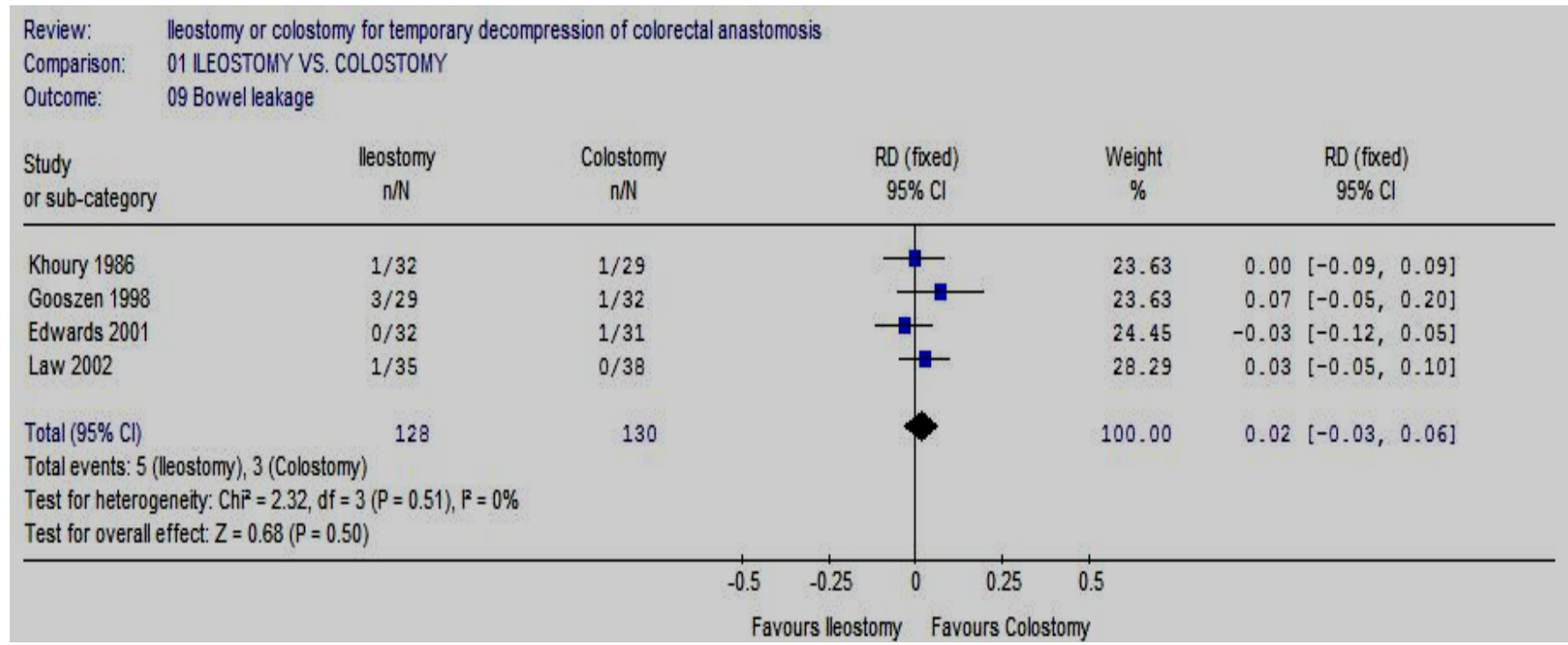

FIGURE 5 - Graph for the outcome of bowel leakage 
D - Outcomes relating to stoma functioning

1. Patient adaptation: six sub-categories were included: - Leakage from appliance: 43\% (36 out 81 patients) in Group A, compared with $48 \%$ (41 out 86 patients) in Group B; RR $0.90,95 \%$ CI: 0.66 to 1.25 (non-significant). There was no statistical heterogeneity in this comparison: heterogeneity chi-square test $=$ $1.93, \mathrm{df}=2, \mathrm{p}=0.38, \mathrm{I}^{2}=0 \%$. Described in three studies ${ }^{11,12,15}$.

2. Skin irritation: 13\% (16 out 123 patients) in Group A, compared with 21\% (26 out 124 patients) in Group B; RR 0.65, 95\% CI: 0.38 to 1.12 (non-significant). There was no statistical heterogeneity in this comparison: heterogeneity chi-square test $=2.11, \mathrm{df}=3, \mathrm{p}=$ $0.55, \mathrm{I}^{2}=0 \%$. Described in four trials $\mathrm{s}^{11,12,14,15}$. 3. Ileus: $6 \%$ ( 3 out 49 patients) in Group A, compared with $2 \%$ ( 1 out 52 patients) in Group B; RD 0.04, 95\% CI: -0.04 to 0.13 (non-significant). There was no statistical heterogeneity in this comparison: heterogeneity chi-square test $=0.02, \mathrm{df}=1, \mathrm{p}=0.89$, $\mathrm{I}^{2}=0 \%$. Described in two trials ${ }^{12,15}$.

\section{Sensitivity analyses}

Studies including emergencies were excluded $^{12}$. Stoma prolapse ${ }^{13,14,15}: 1 \%$ (1 out 93 patients) in Group A, compared with $10 \%$ (9 out 93 patients) in Group B; RD -0.08, $95 \%$ CI: -0.15 to $-0.02(\mathrm{p}=0.02)$. There was no statistical heterogeneity in this comparison: heterogeneity chi-square test $=0.78, \mathrm{df}$ $=2, \mathrm{p}=0.68, \mathrm{I}^{2}=0 \%$ (Figure 6 ).

A summary of the results from all outcomes is showed in Table 5.
TABLE 5 - ILEOSTOMY VS. COLOSTOMY comparison

\begin{tabular}{|c|c|c|c|c|}
\hline Outcome & $\begin{array}{l}\text { No. of } \\
\text { studies }\end{array}$ & $\begin{array}{c}\text { No. of } \\
\text { participants }\end{array}$ & Statistical method & Effect size \\
\hline Mortality & 5 & 319 & $\begin{array}{l}\text { Risk Difference (Fixed) } \\
995 \% \mathrm{Cl}\end{array}$ & $\begin{array}{c}0.02[-0.02 \\
0.05]\end{array}$ \\
\hline Wound infection & 5 & 305 & $\begin{array}{l}\text { Relative Risk (Fixed) } \\
\qquad 95 \% \mathrm{Cl}\end{array}$ & $0.57[0.31,1.07]$ \\
\hline Stoma prolapse & 4 & 256 & $\begin{array}{l}\text { Risk Difference (Fixed) } \\
\qquad 95 \% \mathrm{Cl}\end{array}$ & $\begin{array}{c}-0.17[-0.24,- \\
0.10]\end{array}$ \\
\hline Stoma retraction & 3 & 211 & $\begin{array}{l}\text { Risk Difference (Fixed) } \\
95 \% \mathrm{Cl}\end{array}$ & $\begin{array}{c}0.03[-0.02 \\
0.08]\end{array}$ \\
\hline Parastomal hernia & 3 & 220 & $\begin{array}{l}\text { Risk Difference (Fixed) } \\
\qquad 95 \% \mathrm{Cl}\end{array}$ & $\begin{array}{c}0.01[-0.04 \\
0.06]\end{array}$ \\
\hline Parastomal fistula & 2 & 131 & $\begin{array}{l}\text { Relative Risk (Fixed) } \\
\qquad 95 \% \mathrm{Cl}\end{array}$ & $0.71[0.12,4.17]$ \\
\hline Skin irritation & 4 & 247 & $\begin{array}{l}\text { Relative Risk (Fixed) } \\
95 \% \mathrm{Cl}\end{array}$ & $0.65[0.38,1.12]$ \\
\hline Ileus & 2 & 101 & $\begin{array}{l}\text { Risk Difference (Fixed) } \\
95 \% \mathrm{Cl}\end{array}$ & $\begin{array}{c}0.04[-0.04 \\
0.13]\end{array}$ \\
\hline Bowel leakage & 4 & 258 & $\begin{array}{l}\text { Risk Difference (Fixed) } \\
\qquad 95 \% \mathrm{Cl}\end{array}$ & $\begin{array}{c}0.02[-0.03 \\
0.06]\end{array}$ \\
\hline Reoperation & 2 & 118 & $\begin{array}{l}\text { Risk Difference (Fixed) } \\
95 \% \mathrm{Cl}\end{array}$ & $\begin{array}{c}0.01[-0.06 \\
0.09]\end{array}$ \\
\hline Patient adaptation & 3 & 167 & $\begin{array}{c}\text { Relative Risk (Fixed) } \\
95 \% \mathrm{Cl}\end{array}$ & $0.90[0.66,1.25]$ \\
\hline $\begin{array}{c}\text { Colorectal anastomotic } \\
\text { dehiscence }\end{array}$ & 4 & 250 & $\begin{array}{l}\text { Relative Risk (Fixed) } \\
\qquad 95 \% \mathrm{Cl}\end{array}$ & $0.72[0.36,1.47]$ \\
\hline Incisional hernia & 2 & 103 & $\begin{array}{c}\text { Risk Difference } \\
\text { (Random) } 95 \% \mathrm{Cl}\end{array}$ & $\begin{array}{c}-0.07[-0.26 \\
0.11]\end{array}$ \\
\hline $\begin{array}{c}\text { Postoperative bowel } \\
\text { obstruction }\end{array}$ & 4 & 237 & $\begin{array}{l}\text { Risk Difference (Fixed) } \\
\qquad 95 \% \mathrm{Cl}\end{array}$ & $\begin{array}{c}0.01[-0.05 \\
0.07]\end{array}$ \\
\hline $\begin{array}{l}\text { Sensitivity analysis - } \\
\text { Studies including } \\
\text { emergencies were } \\
\text { excluded - Stoma } \\
\text { prolapse }\end{array}$ & 3 & 186 & $\begin{array}{l}\text { Risk Difference (Fixed) } \\
\qquad 95 \% \mathrm{Cl}\end{array}$ & $\begin{array}{c}-0.08[-0.15,- \\
0.02]\end{array}$ \\
\hline
\end{tabular}

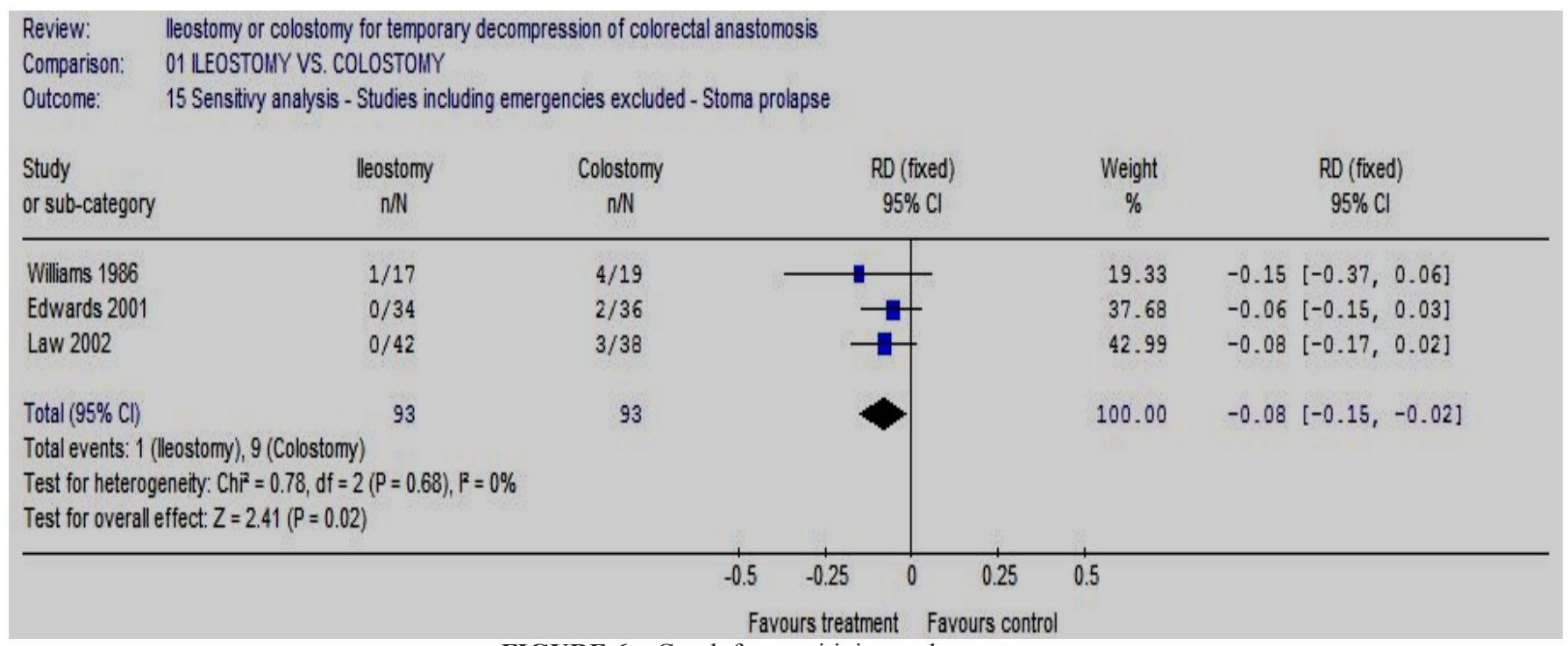

FIGURE 6 - Graph for sensitivity analyses 


\section{Discussion}

\section{A - General outcome measurements}

The overall analysis of this group of outcomes showed that there was no difference in the mortality, wound infection, colorectal anastomotic dehiscence or reoperation, whether patients underwent loop ileostomy or loop colostomy. The inclusion of patients with complications from underlying diseases and emergency surgery is probably not related to any specific type of stoma. This might explain why a greater number of deaths were reported in one of the trials ${ }^{12}$. Colorectal anastomotic dehiscence is considered to be the most important outcome, once the stoma has been constructed. One of the trials ${ }^{12}$ did not analyze this outcome. Because of the limited number of participants included, the reviewers were unable to present meaningful results. It is generally accepted that a loop ileostomy is more difficult to construct than a loop colostomy ${ }^{15,22}$. However, this review was unable to show these difficulties in stoma construction, because the mean difference and the standardized mean difference of the continuous data (time of stoma formation) could not be calculated from the results from the trials.

\section{B - Outcome measurements relating to stoma construction}

Stoma prolapse presented statistical significance but with pronounced heterogeneity between the trials included. Statistical heterogeneity depends on the clinical and methodological differences between trials. Inevitably, studies brought together in a systematic review will differ. Each of the trials included was quality-assessed independently by the reviewers and these assessments were then compared, to try to distinguish the type of heterogeneity. On this occasion, the variability was found in the interventions included in one of the studies, i.e. emergency surgery ${ }^{12}$. Exclusion of the trial that included emergency operations, did not give rise to any more statistical or clinical heterogeneity among the other trials.

The occurrence of parastomal hernia after the construction of a loop ileostomy or loop colostomy depends on the same risk factors as for stoma prolapse and incisional hernia. Thus, the size of the fascia defect and wound infection might be the main initial factors for these complications. This review was unable to show any significant difference in the incidence of that postoperative complication, which occurred in a small number of patients. The available evidence so far does not allow us to conclude that either of the faecal diversion procedures is superior when parastomal hernia is taken into account.

\section{C - Outcome measurements relating to stoma closure}

To analyze the outcome of 'incisional hernia', the random-effect model was applied because the heterogeneity test using the fixed effect-model presented a significant difference. In subjecting the result to random-effect analysis, the reviewers made the assumption that individual studies were estimating different treatment effects, following a certain distribution pattern. The idea of a random-effect meta-analysis is to learn about this distribution of effects across different studies. The heterogeneity among the trials included can be visualized by looking at the inclusion criteria for the participants: one trial ${ }^{15}$ analyzed all patients who underwent elective colorectal surgery regardless of diagnosis, while another ${ }^{13}$ only included patients undergoing anterior resection and total mesorectal excision for rectal cancer. According to one of the studies ${ }^{13}$, loop colostomy appears somewhat easier to close than loop ileostomy. The increased risk of deep wound dehiscence, due to greater contamination of the wound at the time of closure, might be the main factor in this postoperative complication ${ }^{23}$. Alternatively, the spout of an ileostomy may also reduce the leakage of fecal fluid during mobilization of the ileostomy ${ }^{13,15}$. The length of patient follow-up after stoma closure varied among the trials included and must be taken into account when analyzing this outcome. Except for one of the trials ${ }^{11}$, the others reported follow-ups of various lengths: 1 year ${ }^{12}, 2.5$ years ${ }^{15}$ and 5 years ${ }^{13,14}$. It might be expected that any advantage regarding the ease of closure procedures would be reflected in reduction or resection of the ileostomy spout, along with better access to the peritoneal cavity provided by the greater fascia defect in the colostomy, as reported in one of the trials included ${ }^{13}$. We agree with these points, but the lack of statistical significance does not allow us to conclude anything regarding the superiority of one fecal diversion method over the other. The presence of a loop ileostomy may increase the chances of twisting the small bowel and forming adhesions adjacent to the stoma, which may induce postoperative intestinal obstruction ${ }^{24}$. This review did not find any significant difference in the incidence of intestinal obstruction between patients with loop ileostomy and with loop colostomy. However, several trials have reported that loop ileostomy is highly associated with this postoperative complication ${ }^{14,24-28}$. Concerning postoperative bowel obstruction, there is some evidences that, with longer follow-up, adhesion-related complications might become more frequent, particularly after loop ileostomy closure ${ }^{13}$. We also agree with these reports, but further studies will have to be conducted in order to clarify this issue in terms of statistical evidence. The sample size achieved in this review was not great enough to show any significant difference between the two methods of diverting the fecal stream, due to lack of statistical power. Further studies are required to confirm this idea.

\section{D - Outcome measurements relating to stoma functioning}

In terms of stoma management, there is some evidence showing that ileostomy has some theoretical advantages over colostomy. Thus, the ileostomy spout makes effluent collection more efficient, induces a longer time interval between appliance changes, fewer patients complain of odor and the ileostomy site is more visible to the patient ${ }^{15}$. However, these advantages could not be proven in this review because most of the studies did not evaluate these variables. Good patient adaptation and reductions in serious skin problems may be due to skilled and intensive stoma care ${ }^{11}$, by stoma therapists and specialized nurses in the nursing units.

A recent review by Lertsithichai ${ }^{29}$ described the same 
studies, but with an outcome that differed slightly from the present review. The main difference was that it retrieved the trials from MEDLINE and the Cochrane Database of Systematic Reviews, but did not include searches from LILACS and EMBASE. However, both reviews found pronounced heterogeneity between the trials included. The review by Lertsithichai found that neither type of temporary diverting stoma was superior to the other, for all the colorectal patients included.

Special care with the construction of both methods of faecal diversion is highly advised due to the high incidence of complications in clinical practice.

New randomized controlled trials of good quality are needed in order to evaluate which type of temporary defunctioning stoma would be best. It needs to be established why prolapse occurs more frequently with colostomy and what procedure modifications might lessen this risk. Ideally, trials in which patients are undergoing anterior resection and total mesorectal excision for rectal cancer should be conducted. For this clinical question, such trials should exclude patients with proximal rectal cancer in whom the mesorectum was transected and a higher rectal anastomosis was constructed.

\section{Conclusions}

The best available evidence regarding the use of a loop ileostomy or a loop colostomy when decompression of colorectal anastomosis is recommended is inconclusive. So far, the results in terms of the occurrence of stoma prolapse support the choice of loop ileostomy as the technique for faecal diversion for colorectal anastomosis.

\section{References}

1. McArdle CS, McMillan DC, Hole DJ. Impact of anastomotic leakage on long-term survival of patients undergoing curative resection for colorectal cancer. Br J Surg. 2005;92:1150-4.

2. Gastinger I, Marusch F, Steinert R, Wolff S, Koeckerling F, Lippert H. Protective defunctioning stoma in low anterior resection for rectal cancer. Br J Surg. 2005;92:1137-42.

3. Konishi T, Watanabe T, Kishimoto J, Nagawa H. Risk factors for anastomotic leakage after surgery for colorectal cancer: results of prospective surveillance. J Am Coll Surg. 2006;202:439-44.

4. Dehni N, Schlegel RD, Cunningham C, Guiguet M, Tiret E, Parc R. Influence of a defunctioning stoma on leakage rates after low colorectal anastomosis and J pouch-anal anastomosis. Br J Surg. 1998;85:1114-7.

5. Rullier E, Laurent C, Garrelon JL, Michel P, Saric J, Parneix M. Risk factors for anastomotic leakage after resection of rectal cancer. Br J Surg. 1998;85:355-8.

6. Poon RTP, Chu KW, Ho JWC, Chan CW, Law WL, Wong J. Prospective evaluation of selective defunctioning stoma for low anterior resection with total mesorectal excision. World J Surg. 1999;23:463-8.

7. Alberts JC, Parvaiz A, Moran BJ. Predicting risk and diminishing the consequences of anastomotic dehiscence following rectal resection. Colorectal Dis. 2003;5:478-82.
8. Peeters KCMJ, Tollenaar RAEM, Marijnen CAM, Kranenbarg EK, Steup WH, Wiggers T, et al. Risk factors for anastomotic failure after total mesorectal excision of rectal cancer. Br J Surg. 2005;92:211-6.

9. Matthiessen P, Hallböök O, Rutergard J, Simert G, Sjödahl R. Defunctioning stoma reduces symptomatic anastomotic leakage after low anterior resection of the rectum for cancer. Ann Surg. 2007;246:207-14.

10. Hool GR, Church JM, Fazio VW. Decision-Making in Rectal Cancer Surgery. Dis Colon Rectum. 1998;41:147-52.

11. Khoury GA, Lewis MC, Meleagros L, Lewis AA. Colostomy or ileostomy after colorectal anastomosis? A randomized trial. Ann R Coll Surg Engl. 1986;69:5-7.

12. Gooszen AW, Geelkerken RH, Hernans J, Lagaay MB, Gooszen HG. Temporary decompression after colorectal surgery: randomized comparison of loop ileostomy and loop colostomy. Br J Surg. 1998;85:76-9.

13. Edwards DP, Leppington-Clarke A, Sexton R, Heald RJ, Moran BJ. Stoma-related complications are more frequent after transverse colostomy than loop ileostomy: a prospective randomized clinical trial. Br J Surg. 2001;88:360-3.

14. Law WL, Chu KW, Choi K. Randomized clinical trial comparing loop ileostomy and loop transverse colostomy for fecal diversion following total mesorectal excision. Br J Surg. 2002;89:704-8.

15. Williams NS, Nasmyth DG, Jones D, Smith AH. Defunctioning stomas: a prospective controlled trial comparing loop ileostomy with loop transverse colostomy. Br J Surg. 1986;73:566-70.

16. Wexner SD, Taranow DA, Johansen OB, Itzkowitz F, Daniel N, Nogueras JJ. Loop ileostomy is a safe option for fecal diversion. Dis Colon Rectum. 1993;36:349-54.

17. Torkington J, Khetan N, Jamison MH. Temporary decompression after colorectal surgery: randomized comparison of loop ileostomy and loop colostomy [letter]. Br J Surg. 1998;85:1452.

18. O’Leary DP, Fide CJ, Foy C, Lucarotti ME. Quality of life after low anterior resection with total mesorectal excision and temporary loop ileostomy for rectal carcinoma. Br J Surg. 2001;88:1216-20.

19. Göhring U, Lehner B, Schlag P. Ileostomy versus colostomy as temporary deviation stoma in relation to stoma closure. Chirurg. 1988;59(12):842-44.

20. Silva MA, Ratnayake G, Deen KI. Quality of life of stoma patients: temporary ileostomy versus colostomy. World J Surg. 2003;27(4):421-4.

21. Gooszen AW, Geelkerken RH, Hermans J, Lagaay MB, Gooszen HG. Quality of life with a temporary stoma. Ileostomy vs. Colostomy. Dis Colon Rectum. 2000;43:650-5.

22. Hawley PR, Ritchie JK. The colon. Clin Gastroenterol. 1979;8:403-15.

Higgins JPT, Thompson SG, Deeks JJ, Altman DG. BMJ. 2003;327:557-60.

23. Lewis A, Weeden D. Early closure of transverse loop colostomy. Ann R Surg Engl. 1982;64:57-8.

24. Metcalf AM, Dozois RR, beart RW, Kelly KA, Wolff BG. Temporary ileostomy for ileal pouch anastomosis. Function and 
complications. Dis Colon Rectum. 1986;29:300-3.

25. Feinberg SM, McLeod RS, Cohen Z. Complications of loop ileostomy. Am J Surg. 1987;153:102-7.

26. François Y, Dozois RR, Kelly KA, Beart RW, Wolff BG, Pemberton JH. Small intestinal obstruction complicating ileal pouch-anal anastomosis. Ann Surg. 1989;209:46-50.

27. Mann LJ, Stewart PJ, Goodwin RJ, Chapuis PH, Bokey EL. Complications following closure of loop ileostomy. Aust N Z J Surg. 1991;61:493-6.

28. Phang PT, Hain JM, Perez-Ramirez JJ, Madoff RD, Gemlo BT. Techniques and complications of ileostomy takedown. Am J Surg. 1999; 177:463-6.

29. Lertsithichai P, Rattanapichart P. Temporary ileostomy versus temporary colostomy: a meta-analysis of complications. Asian J Surg. 2004;27(3):202-10.
The protocol of this review has been published in The Cochrane Library as: Matos D \& Lustosa SASL. Ileostomy or colostomy for temporary decompression of colorectal anastomosis. Protocol for a Cohrane Review. Cochrane Database of Systematic Review, 2004 (1); CD004647.

A more comprehensive version of this review will be found The Cochrane Library as: Güenaga KF, Lustosa SAS, Saad SS, Saconato H, Matos D. Ileostomy or colostomy for temporary decompression of colorectal anastomosis. Cochrane Database of Systematic Reviews 2007, Issue 1. Art. No.: CD004647. DOI: 10.1002/14651858.CD004647.pub2

\section{Correspondence:}

Conflict of interest: none

Katia Ferreira Guenaga

R. Dr. Vitor de Lamare, 33/21

11045-340 Santos - São Paulo Brazil

Phone: (55 13)3289-5094 / 9788-8172

Received: November 19, 2007

kfg012@terra.com.br

Review: January 23, 2008

Accepted: February 19, 2008

\section{How to cite this article}

Güenaga KF, Lustosa SAS, Saad SS, Saconato H, Matos D. Ileostomy or colostomy for temporary decompression of colorectal anastomosis. Systematic review and meta-analysis. Acta Cir Bras. [serial on the Internet] 2008 May-June;23(3). Available from URL: http://www.scielo.br/acb

*Color figure available from www.scielo.br/acb 